term or long term treatment with continuous ambulatory peritoneal dialysis. The small difference may be related to the number of transplant operations performed in patients who received short term treatment.

Complications after transplantation related to continuous ambulatory peritoneal dialysis were minimal. Only one episode of peritonitis was observed, which was easily treated with intraperitoneal antibiotics. Cramer et al reported the development of peritonitis after transplantation in one patient who received continuous ambulatory peritoneal dialysis who had never had an episode of peritonitis before transplantation, indicating a risk of activation of subclinical peritonitis in an immunosuppressed patient. ${ }^{9}$ This was not observed by us or others. ${ }^{610}$ Eight of our 42 patients who had had at least four episodes of peritonitis before transplantation, and who could, therefore, be considered to be patients at high risk, had no apparent peritoneal infection after transplantation.

The routine maintenance of the indwelling Tenckhoff catheter after transplantation was not a problem. It was used by choice in four of 19 patients who required dialysis in the immediate postoperative period. Those catheters that were not removed at the time of transplantation were withdrawn after a mean of three months when the graft function was stable. The operation was uneventful, and in 15 patients it was performed at the same time as removal of the ureteric stent at cystoscopy.

In conclusion, continuous ambulatory peritoneal dialysis is not an impediment to successful renal transplantation. The risk of peritonitis after transplantation should be borne in mind in patients treated with continuous ambulatory peritoneal dialysis, and even in the absence of clinical signs we would advise routine sampling of peritoneal fluid for bacteriological study.
The Tenckhoff catheter can be used to perform dialysis in those who do not have immediate graft function. Short term treatment with continuous ambulatory peritoneal dialysis is an excellent mode of treatment as a "parking place" for patients awaiting renal transplantation, which does not take up places in renal units, allows patients home in a week or two, and has minimal capital costs.

Joao B Evangelista Jr received support from the British Council during this study and David Bennett-Jones from Travenol UK. We thank all members of the renal unit staff who cared for these patients.

\section{References \\ 1 Kramer P, Broyer M, Brunner FP, et al. Combined report on regular dialysis and transplantation in Europe XiV. Proc Eur Dial Transplant Assoc 1985;21: \\ 2 Papadakis J, Brown CB, Cameron JS, et al. A prospective controlled trial of "high" versus "low" dose corticosteroid in transfused recipients of cadaver Peto R, Pike MC, Armitage P, et al. Design and analysis of randomised clinical rial requiring prolonged observations of each patient. II Analysis and examples. Br F Cancer 1977;35:1-39. \\ 4 Taube DH, Williams DG, Cameron JS, et al. Renal transplantation after removal and prevention of resynthesis of HLA antibodies. Lancet 1984 ; i:824-6. \\ Rigby RJ, Butler JL, Petrie JJB. Experience with continuous ambulatory peri- \\ toneal dialysis. Med $\mathcal{f}$ Aust $1982 ; \mathrm{i}: 331$.
6 Rigby RJ, Petrie JJ. Experience of transplantation in patients on continuous ambulatory peritoneal dialysis (CAPD). Transplantation 1984;37:533. \\ Wood C, Thomson NM, Scott DF, Holdsworth Field, Rich, and Associates (in press) \\ 8 Shapira Z, Shmueli D, Yussim A, Boner G, Haimovitz C, Servadio C. Kidney ransplantation in patients on continuous ambulatory peritoneal dialysis. Proc Eur Dial Transplant Assoc 1984;21:932-5. \\ 9 Cramer SO, Adams MB, Kauffman JRHM. Post-transplant peritonitis in a CAPD \\ 10 Patel S, Rosenthal JT, Hakala TR. Management of the peritoneal dialysis catheter after transplantation. Transplantation 1983;36:589-90.}

\title{
Process and outcome of care for patients with ovarian cancer
}

\author{
A LIBERATI, C MANGIONI, L BRATINA, G CARINELLI, S MARSONI, F PARAZZINI, \\ M REGALLO, R TALAMINI, G TOGNONI
}

\begin{abstract}
The process and outcome of care for a group of patients with ovarian cancer treated over two years in two groups of Italian general hospitals were investigated. The quality of diagnostic and therapeutic measures did not substantially differ in specialised and non-specialised centres when selected indicators of quality of care were examined. Similarly, no differences in survival emerged for the two
\end{abstract}

Istituto di Ricerche Farmacologiche "Mario Negri," Milan, Italy A LIBERATI, MD, senior investigator

$S$ MARSONI, MD, research associate

F PARAZZINI, MD, research fellow

G TOGNONI, MD, head, laboratory of clinical pharmacology

Prima Clinica Ostetrica e Ginecologica dell' Universita di Milano, Ospedale "S Gerardo" Monza, Milan

C MANGIONI, MD, head of department of obstetrics and gynaecology

L BRATINA, MD, head of pathology department

M REGALLO, MD, research fellow

Istituti Clinici di Perfezionamento Università di Milano

G CARINELLI, MD, head of pathology department

Centro Riferimento Oncologico-USL, 33081 Aviano

R TALAMINI, PHD, research fellow

Correspondence to: Dr Liberati. groups of hospitals. Overall results of the Italian series compared well with statistics of survival published by international centres for cancer, suggesting that when the yield of available treatments is limited both the process and outcome of care should be evaluated to obtain a reliable picture of quality of care. In the light of these results there are useful implications for planning future clinical trials and ways of caring.

\section{Introduction}

Although ovarian cancer is only the fourth most common cause of death from cancer in women, it is the major cause of death from a gynaecological malignancy in most developed countries. ${ }^{1}$ Despite claims of effective treatment in many reports of clinical trials, ${ }^{2}{ }^{3}$ statistics of survival do not indicate any substantial improvements in the management of the disease. ${ }^{45}$

The real yield of experimental treatments tested in randomised controlled trials is difficult to assess mainly because of the selection of patients and low quality of design and implementation of most of them, as has been recently documented. ${ }^{5}$ Poor compliance to key procedures, specifically understaging, is one factor causing the low impact of potentially effective treatments on cure and prolongation of survival. ${ }^{6}$

In 1979 in Italy we started a monitoring programme aimed at evaluating the process of care in patients with different malig- 
nancies seen at institutions with varying degrees of organisation and skill. The findings have already been reported for cancer of the breast ${ }^{7}$ and lung. ${ }^{8}$ For ovarian cancer the study of the quality of care was extended to investigate its impact on the clinical outcome in terms of survival. The results are discussed here, also from the point of view of their possible implications in the planning of future clinical trials and ways of caring.

\section{Patients and methods}

Because the surveys of process and outcome had different goals and methodology they are described separately.

\section{SURVEY OF PROCESS}

This consisted of a retrospective chart audit of all patients admitted with the diagnosis of ovarian cancer to one of the 31 participating centres over two years (1978-9). Explicit criteria defining norms of diagnostic and therapeutic care considered feasible and acceptable diagnosis. To minimise bias stricter criteria of eligibility to evaluate outcome were used, which improved the comparison of those in our series with those already reported. Thus a patient entered the study of $\varrho$ outcome only if she met the following criteria: diagnosed as having primary epithelial ovarian cancer at one of the participating hospitals between 1 January 1978 and 31 December 1979 and had available $\bar{J}$ pathological specimens to confirm the diagnosis or a statement in the D operative summary that no biopsy was performed but malignant $\mathbb{D}$ tumour of ovarian origin was macroscopically evident at explorative $m$ surgery. Through these criteria 174 patients (aged 29-84, median 58) entered the study of outcome-that is, $66 \%$ of the original group.

The operative summaries, pathology slides, and all clinical charts $\omega$ were requested from participating hospitals. One clinician and two $\bar{C}$ pathologists independently reviewed the material to confirm the $\frac{C}{\partial}$ diagnosis of primary epithelial ovarian cancer and define, when $\overline{\bar{N}}$ possible, the pathological stage at surgery with the information from $\mathbb{\phi}$ the operative summaries.

Among the 103 patients who were considered in the survey of process but did not meet the criteria for inclusion in the study of outcome, $\vec{O}$ reasons for non-eligibility were as follows: $37(13 \%)$ were first diagnosed before January $1978 ; 16(6 \%)$ had metastatic ovarian $\vec{\omega}$ carcinoma from either a genital or extragenital site; $15(5 \%)$ had non- $\stackrel{\circ}{\circ}$

TABLE I-Comparison of patients treated in hospitals with and without oncology services, according to selected indicators of care. (Values are numbers (\%) of cases)

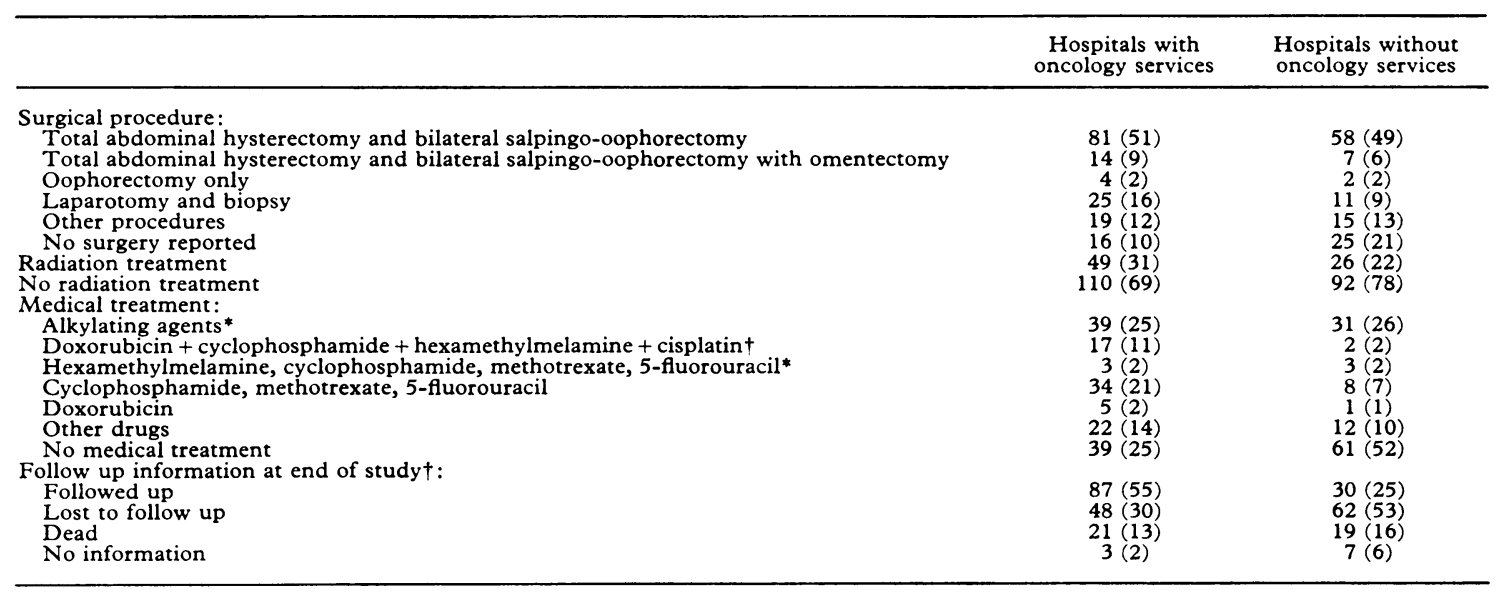

* Regimens considered acceptable by our criteria of quality.
+ Six patients not included because they were at first admission at end of study of process.

for institutions not orientated for research were established through published reports and peer review. The final format of these criteria was incorporated in a questionnaire listing items whose positive or negative reporting in the clinical charts was assessed by a group of medically qualified investigators, trained and tested for comparative reliability in retrieving data. To evaluate care all the visits by inpatients and outpatients for management of the disease represented the units of observation.

The quality of the diagnostic approach was quantitatively assessed by measuring the proportion of cases for which essential items, such as histological classification and pathological stage of disease, were reported in the charts. Appropriateness of therapeutic management was evaluated with reference to the type of surgical procedure, chemotherapy regimen, and completeness of follow up.

In particular, among surgical procedures the standard treatment was total abdominal hysterectomy and bilateral salpingo-oophorectomy with or without omentectomy, while the following chemotherapy regimens were indicators of good care: any single alkylating agent; hexamethylmelamine, cyclophosphamide, methotrexate, 5fluorouracil (HEXA CAF); and the combination of doxorubicin and cyclophosphamide (AC) with or without hexamethylmelamine and cisplatin. Finally, follow up was assessed from the proportion of patients still under regular care at the end of the study.

\section{SURVEY OF OUTCOME}

Because assessment of survival was the scope of the survey of outcome we made additional inquiries to assess the validity of the initial epithelial ovarian tumours such as dysgerminoma and granulosa and germ cell tumours; $4(1 \%)$ had benign neoplasm; and $31(12 \%)$ could not be traced as they were lost to follow up at the hospital, or information on their vital state was unavailable because of inconsistencies in demographic data. Thus 72 cases $(26 \%)$ were excluded by design and $31(12 \%)$ because of missing data. The group with missing data $O$ could have been eligible for the survey of outcome and the estimates of survival might have been different had they been included.

Information on vital state was traced through death certificates requested from the registry office of the town of residence. The last $\mathrm{O}$ patient included in the evaluation of survival was diagnosed in Novem- $\rightarrow$ ber 1979, and information on vital state was updated as of November 1983. In the five year estimates of survival, therefore, each patient $N$ could have been followed up for at least four full years. Survival N curves were produced by the life table methods and compared in some $\omega$ subgroups. Significant differences between these curves were examined with the log rank test. The end points of interest in the curves were classified as deaths due to ovarian cancer, neoplastic disease not other- $\mathbb{D}$ wise specified, and cardiopulmonary arrest. Tests of significance for ${ }^{?}$ contingency tables were based on the usual $\chi^{2}$ value, comparing $\underline{T}$ observed and expected numbers of events. Differences were considered significant at $\mathrm{p}<0.05$.

Results of the surveys of process and outcome are presented both of all cases and separately for the two groups of hospitals according to the presence or absence of in house facilities for the care of patients with cancer. We used the proportion of standard surgical procedures, $\varnothing$ acceptable chemotherapy regimens, and patients still followed up at the end of the study as indicators of good quality of care. Other items, such as the proportion of patients with complete information on surgi- 
cal and medical management, reflecting good reporting in the clinical charts were examined separately.

\section{Results}

SURVEY OF PROCESS: RESULTS OF ALL CASES AND BY GROUPS OF HOSPITALS

Substantial variation was found with respect to the type and number of entries of selected information in patients' records. Of the 277 patients (median age 58 (range 25-84)) with ovarian cancer, $18(7 \%)$ had stages I and II; $59(21 \%)$ stages III and IV; $200(72 \%)$ stage no reported; $82(30 \%)$ serous; $29(11 \%)$ mucinous; $26(9 \%)$ endometrioid $8(3 \%)$ undifferentiated; $55(20 \%)$ epithelial (not otherwise specified) $15(5 \%)$ non-epithelial; and $62(22 \%)$ not reported. While a standard histological classification was reported in $215(78 \%)$ cases, a standard classification of stage was present in the charts of only $77(28 \%)$ patients.

Better quality was found regarding surgical procedures. Although some techniques such as omentectomy, relevant for more accurate staging, had not entered general hospital practice, the quality of surgical management appeared to be generally acceptable : $160(58 \%)$ patients received the standard type of management (reference should be made to the time at which patients were first diagnosed and treated), $76(27 \%)$ received a partial procedure, and for $41(15 \%)$ no information was available about surgical management. Of the 36 patients for whom laparotomy and biopsy were reported, 20 were aged over 70 or had inoperable disease at surgery, while for the remaining 16 no information useful for evaluating appropriateness of care was available.

In respect of medical treatment, $95(52 \%)$ patients received a regimen that was acceptable by our criteria. Monochemotherapy with an alkylating agent was the form of treatment most widely used (70 patients $(38 \%)$ ) even in advanced cases, while only 25 patients $(14 \%)$ were treated with a more aggressive regimen. Almost half of the patients given chemotherapy $(90(48 \%))$ received a poorly active regimen of single or multiple drugs (doxorubicin alone, cyclophosphamide, methotrexate, 5-fluorouracil (HEXA-CAF), or other types of drugs grouped under the category "others"). A third of the patients $(100(36 \%))$ did not receive any medical treatment.

The follow up seemed to be particularly unsatisfactory: for 125 $(46 \%)$ patients no information was given in the charts after periods of follow up varying from three to 24 months (table I). No major differences in quality of care in the two groups of hospitals emerged

TABLE II-Clinical characteristics and indicators of care of $174^{*}$ patients with ovarian cancer included in outcome survey: all cases and by hospital groups. (Values are numbers (\%) of cases)

\begin{tabular}{lccc}
\hline & All cases & $\begin{array}{c}\text { Hospitals with } \\
\text { oncology services }\end{array}$ & $\begin{array}{c}\text { Hospitals without } \\
\text { oncology services }\end{array}$ \\
\hline $\begin{array}{l}\text { Median age (and range) (years) } \\
\text { Characteristics: }\end{array}$ & $57(29-84)$ & $57(29-84)$ & $58(41-82)$ \\
Stage I-II & $68(39)$ & $31(36)$ & $30(41)$ \\
Stage III-IV & $88(51)$ & $50(56)$ & $32(46)$ \\
Stage not evaluable & $18(10)$ & $7(8)$ & $9(13)$ \\
Serous & $67(42)$ & $37(42)$ & $29(42)$ \\
Mucinous & $13(8)$ & $6(7)$ & $6(8)$ \\
Endometrioid & $19(12)$ & $10(14)$ & $4(11)$ \\
Undifferentiated & $9(6)$ & $4(5)$ & $4(6)$ \\
Epithelial (not otherwise specified) & $30(19)$ & $17(19)$ & $13(19)$ \\
Not evaluable & $21(13)$ & $11(13)$ & $10(14)$ \\
Indicators of care: & $154(89)$ & $80(91)$ & $61(86)$ \\
Surgery performed & $85(55) \ddagger$ & $46(58) \ddagger$ & $31(51) \ddagger$ \\
Standard (radical) surgery $\dagger$ & $121(70)$ & $68(77) \ddagger$ & $47(66) \ddagger$ \\
Chemotherapy performed & $73(60) \ddagger$ & $36(54) \ddagger$ & $24(65) \ddagger$ \\
Chemotherapy by acceptable regimens & $45(26)$ & $24(30)$ & $16(23)$ \\
Aadiotherapy performed & $52(30)$ & $26(30)$ & $22(31)$ \\
Alive at end of follow up & & \\
\hline
\end{tabular}

*Fifteen patients were not considered in analysis by hospital group as they were treated in centres not classifiable in terms of organisation of oncology (see Patients and methods) (age 43-80, median 61). $\$$ †Percentages of total number treated in respective group.

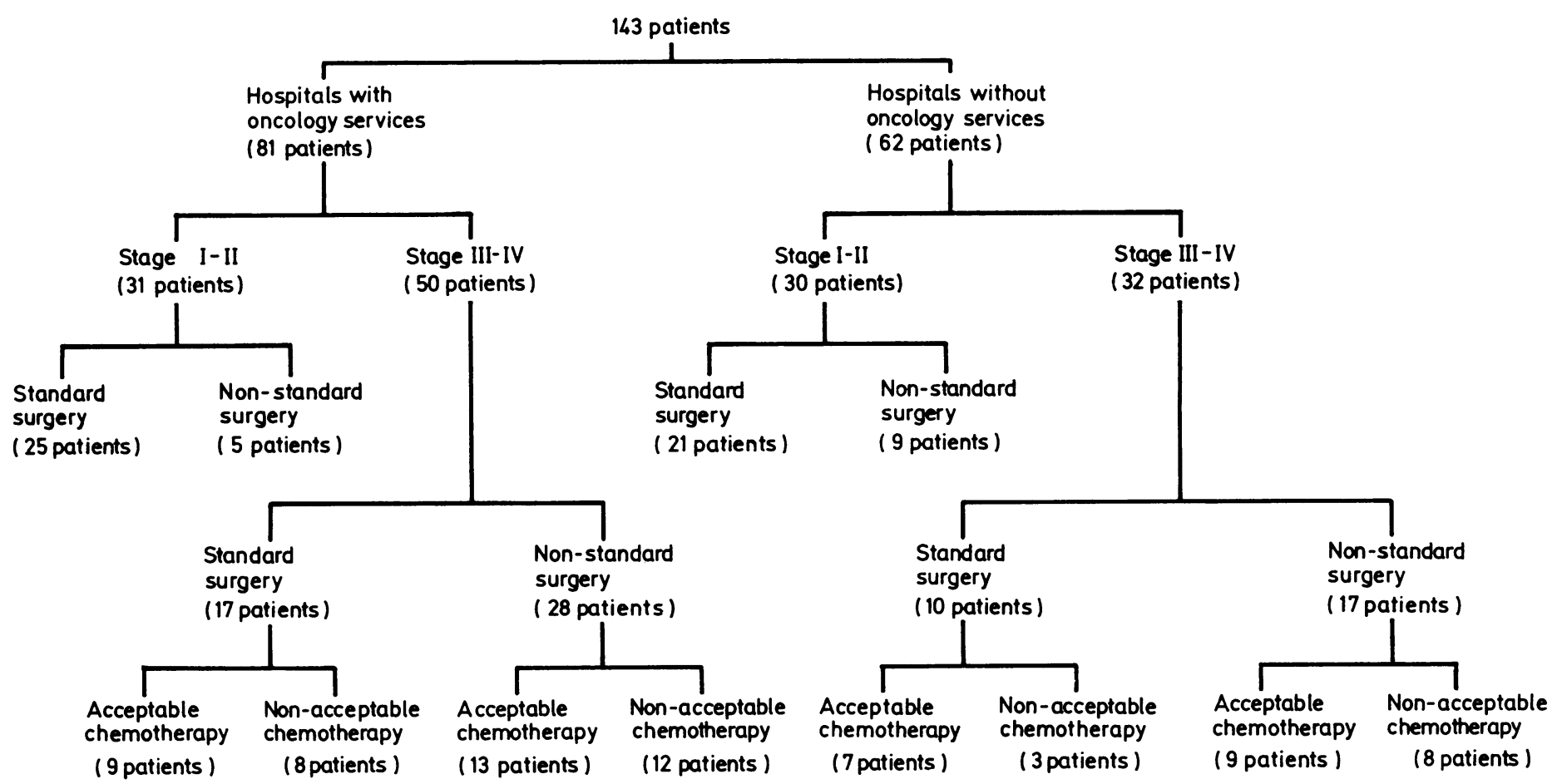

FIG 1-Quality of care for 143 patients with pathologically confirmed epithelial ovarian cancer, excluding 16 patients with stage of cancer not evaluable and 15 treated in hospitals not classifiable in terms of organisation of oncology (see Patients and methods). 
when seiected indicators of quality were examined. The proportions of standard surgical procedures and acceptable chemotherapy regimens were slightly higher $(60 \% v 55 \%$ and $37 \% v 28 \%)$ in more specialised institutions, but differences were never significant $\left(\chi^{2}{ }_{1}=\right.$ 1.60 and 1.31 , respectively). Similarly, the proportions of patients treated with radiotherapy in the two groups of hospitals did not differ $\left(31 \% v 22 \%, \chi^{2}{ }_{1}=2 \cdot 65, \mathrm{p}=\mathrm{NS}\right)$. The only significant difference was in the proportions of patients still followed up at the end of the study, who were from the more specialised institutions $\left(55 \% v 25 \%, \chi^{2}{ }_{1}=\right.$ $23 \cdot 8, \mathrm{p}<0 \cdot 001)$.

When items reflecting the quality of reporting of information in the clinical charts were considered, hospitals with oncology facilities fared better than those without. The proportion of patients with complete information on surgical and medical management was significantly higher in more specialised centres, $21 \% v 10 \%$ and $52 \% v$ $25 \%$, respectively; $\chi^{2}{ }_{1}=6.65, \mathrm{p}<0.01$ and $\left.\chi^{2}{ }_{1}=16.91, \mathrm{p}<0.001\right)$.
SURVEY OF OUTCOME: GENERAL FINDINGS AND HOSPITAL PERFORMANCES

Table II gives a general description of clinical characteristics and $C$ indicators of care of patients in the survey of outcome, both of all $\widehat{\widehat{\Omega}}$ cases and by groups of hospitals. The only noteworthy difference from the study of process was in the larger proportion of patients with an $D$ evaluable stage of disease $(90 \% v 28 \%)$.

The patients' characteristics did not differ significantly in more and less specialised institutions in terms of age (median 57 and 58 years), stage $\left(\chi^{2}{ }_{1}=2 \cdot 23\right)$, and distribution of histotypes $\left(\chi^{2}{ }_{1}=0.51\right)$. Similarly, $\ddot{\vec{z}}$ no significant differences emerged in proportions of patients undergoing a standard surgical procedure $\left(\chi^{2}{ }_{1}=0.62\right)$ or receiving acceptable $\bar{O}$ chemotherapy $\left(x^{2}{ }_{1}=1.94\right)$ in these two settings of care. Figure $1 \frac{\bar{O}}{\sigma}$ examines more closely the quality of the therapeutic approach by $\overline{\bar{\omega}}$ groups of hospitals for the 143 patients included in the survey of out-

TABLE III-Rates of survival of 174 patients with ovarian cancer included in the survey of outcome: all cases* and by groups of hospitals. $\dagger$ (Yearly survival figures are \% (SE) of patients)

\begin{tabular}{|c|c|c|c|c|c|c|c|}
\hline \multirow[b]{2}{*}{ Stage } & \multirow{2}{*}{$\begin{array}{l}\text { No of } \\
\text { patients }\end{array}$} & \multirow{2}{*}{$\begin{array}{c}\text { Median survival } \\
\text { (months) }\end{array}$} & \multicolumn{5}{|c|}{ Year } \\
\hline & & & 1 & 2 & 3 & 4 & 5 \\
\hline \multicolumn{8}{|c|}{ All cases } \\
\hline $\begin{array}{l}\text { I-II } \\
\text { III-IV } \\
\text { All cases* }\end{array}$ & $\begin{array}{r}68 \\
88 \\
174\end{array}$ & $\begin{array}{l}80+ \\
12 \cdot 7 \\
29 \cdot 8\end{array}$ & $\begin{array}{l}94(3) \\
49(6) \\
64(4)\end{array}$ & $\begin{array}{l}86(4) \\
33(5) \\
51(4)\end{array}$ & $\begin{array}{l}75(6) \\
23(5) \\
42(4)\end{array}$ & $\begin{array}{l}66(6) \\
19(5) \\
37(4)\end{array}$ & $\begin{array}{l}63(7) \\
16(4) \\
35(4)\end{array}$ \\
\hline \multicolumn{8}{|c|}{ Hospitals with oncology facilities } \\
\hline $\begin{array}{l}\text { I-II } \\
\text { III-IV } \\
\text { All casesł }\end{array}$ & $\begin{array}{l}31 \\
50 \\
88\end{array}$ & $\begin{array}{l}72+ \\
18 \cdot 3 \\
32 \cdot 5\end{array}$ & $\begin{array}{l}97(3) \\
53(7) \\
68(5)\end{array}$ & $\begin{array}{l}89(6) \\
34(7) \\
55(6)\end{array}$ & $\begin{array}{l}78(8) \\
24(7) \\
44(6)\end{array}$ & $\begin{array}{l}64(10) \\
20(6) \\
35(6)\end{array}$ & $\begin{array}{l}64(10) \\
17(6) \\
35(6)\end{array}$ \\
\hline \multicolumn{8}{|c|}{ Hospitals without oncology facilities } \\
\hline $\begin{array}{l}\text { I-II } \\
\text { III-IV } \\
\text { All casest }\end{array}$ & $\begin{array}{l}30 \\
32 \\
71\end{array}$ & $\begin{array}{r}80+ \\
8 \cdot 6 \\
25 \cdot 4\end{array}$ & $\begin{array}{l}90(67) \\
40(9) \\
58(6)\end{array}$ & $\begin{array}{l}76(8) \\
29(9) \\
47(6)\end{array}$ & $\begin{array}{l}72(8) \\
17(7) \\
41(6)\end{array}$ & $\begin{array}{l}69(9) \\
13(7) \\
37(6)\end{array}$ & $\begin{array}{l}63(10) \\
13(7) \\
36(6)\end{array}$ \\
\hline
\end{tabular}

*Eighteen patients with stage of disease not evaluable were included in analysis for all cases: median survival 9.4 months; 29 *Eighteen patients with stage of disease not evaluable were included
$(11 \%)$ each in years 1 and 2 ; and $22(10.5 \%)$ each in years 3 to 5 . $(11 \%)$ each in years 1 and 2 ; and $22(10.5 \%)$ each in years 3 to 5 .
+ Fifteen patients treated in hospitals not classified in either category were excluded from this analysis. $\neq$ Seven patients in group with oncological facilities and nine in group without had no classification of stage and were therefore included only in this group.

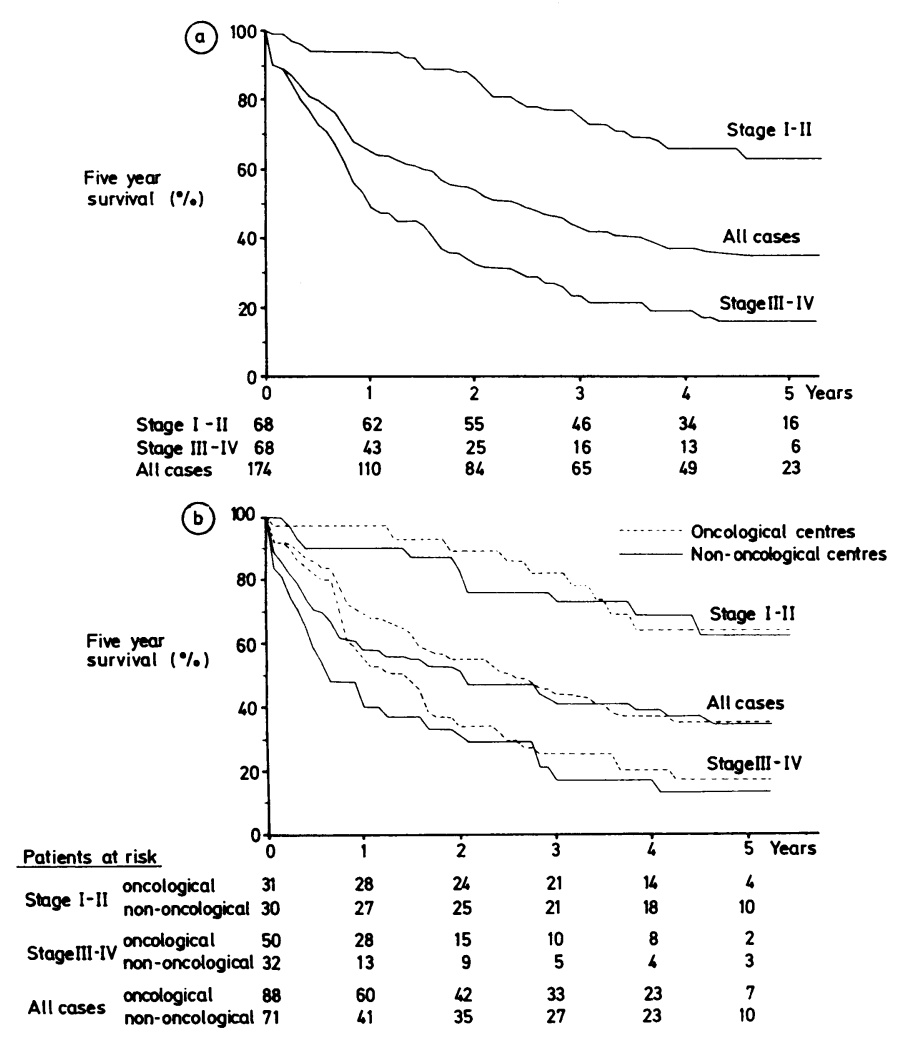

FIG 2-Survival of 174 patients with ovarian cancer according to stages and groups of hospitals. come for whom the stage of disease was evaluable. In agreement with the survey of process again no significant differences in quality of care emerged between centres. In the early stages (I and II) 25 out $\mathbb{D}$ of 31 patients treated in specialised institutions and 21 out of 30 from non-specialised centres underwent a standard surgical procedure. In the advanced stages (III and IV) only nine out of 50 patients from specialised hospitals and seven out of 32 from institutions without oncology services underwent standard surgery and an acceptable chemotherapy regimen. Among acceptable chemotherapy regimens, multidrug regimens containing cisplatin were slightly more common in specialised centres, while monochemotherapy with an alkylating agent occurred more often in less specialised institutions. The duration of chemotherapy was comparable (median 4.5 and 4.1 months in more and less specialised hospitals, respectively). Figure $O$ 2 shows the survival of patients in the survey of outcome with results for the whole series and by groups of hospitals. Table III shows rates 은 of survival at yearly intervals. At five years no difference was evident $\mathrm{N}$ between patients treated in the two groups of hospitals $35 \%$ in on oncology centres $v 36 \%$ in those without oncological facilities; $\chi^{2}{ }_{1} \log \frac{D}{0}$ rank $=0 \cdot 26$ ). Similarly, no differences emerged when patients with earlier stages and those with more advanced disease were examined $N$ separately $\left(\chi^{2}{ }_{1}\right.$ long rank $=0 \cdot 10$ and $1 \cdot 14$, respectively).

Figure 3 compares the survival of Italian patients with results from some major institutions around the world. ${ }^{9}$ Survival was comparable to reference data for both earlier (stage I) and advanced (stage III) cases. According to the median values, survival of our series was $\mathbb{\Phi}$ slightly higher for advanced stages and slightly lower for patients: in the early stages of disease.

\section{Discussion}

The results and implications of this study must be viewed in the light of the crucial finding that quality of care does not have any impact on outcome for patients with cancer of the ovary. This holds true irrespective of the setting. In fact oncology 
BRITISH MEDICAL JOURNAL VOLUME 291 12 OCTOBER 1985

centres did not show a better process or outcome of care despite the fact that, if present, the potential bias due to understaging (likely to be more common in less specialised institutions) would have favoured oncology hospitals as regards the survival of patients with early stage disease (see table III). If true this finding has many implications and is worth looking at in detail.

It is important in clinical experimentation and practice to limits its applicability. When reference is made to the data presented on cancer of the ovaries it seems that the links between process and outcome cannot be affirmed, at least for diseases whose treatments still lack hard evidence of effectiveness. As the statistical power of our findings is based on small numbers this statement on its own is pretentious, and we cannot deny that with more patients a difference might have been found in the performance of the two types of institutions.

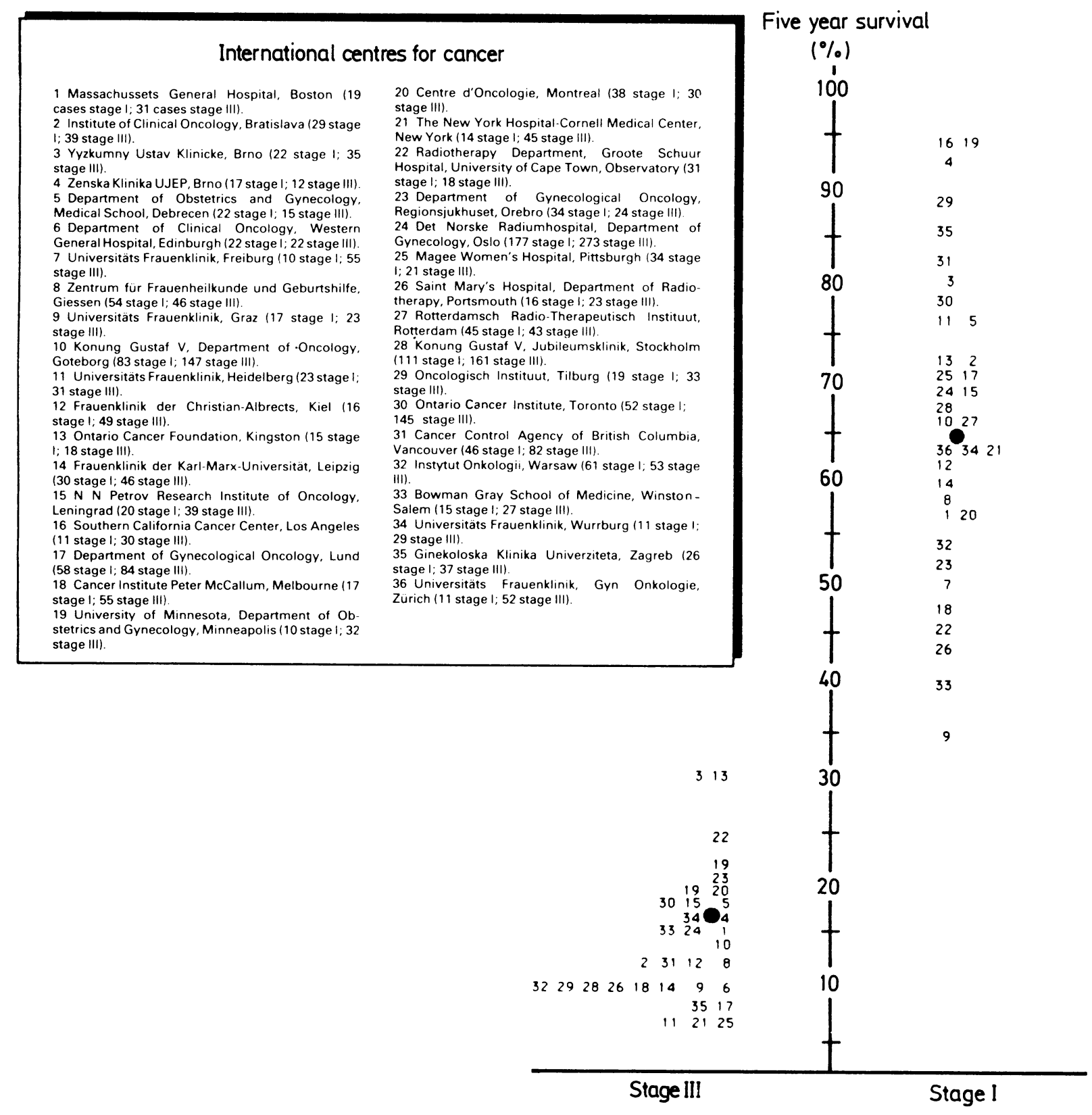

FIG 3-Comparison of five year survival of patients with stage I and stage III ovarian cancer treated in Italian institutions (O) and international centres for cancer (numbers).

call for rigorous observation of chemotherapy regimens, assume the best ratio of benefit and risk to each patient, and produce truly informative data on the disease that is treated. Most chemotherapeutic schedules are, however, burdensome with respect to the quality of clinical and daily life and in the load they impose on health structures. Studies on the quality of care lay great emphasis on the effects of poor clinical practice on outcome. The integrated approach applied in this study, when quality of process and outcome were assessed in the same population, casts strong doubt on this assumption or at least
A recent exhaustive analysis of published reports on clinical trials, however, concluded that the quality of clinical research is, if possible, even worse. ${ }^{5}$ Controlled trials are far from satisfactory numerically and are therefore often unable to show or refute the effectiveness of the treatment under investigation. The implications of this way of reasoning may be many. When reference data are uncertain and poor their transfer to clinical practice is fraught with doubt. Experience in the opposite direction, represented by Hodgkin's lymphoma, when a consistent pattern of recommendations and accepted procedures does exist, 
shows that data worthy of confidence attract reliable, imitative, routine clinical practice. ${ }^{10}$

Compliance to standard regimens must, therefore, be judged by completely different criteria, according to the type of disease and treatment. Far from being a failure poor compliance in cancer of the ovaries might in some instances, seen from the hard end point of the outcome, be considered to be a defensive reaction against a burden of intervention that appears unjustified. It should be clear that omitting some parts of a regimen does not automatically mean a better quality of life for the patient, such as fewer side effects, but simply the exposure to causally linked procedures, which could entail worse side effects without assuring minimal benefits. ${ }^{11} 12$

Improving the situation does not therefore rest in trying to educate general hospitals to adopt standards of research or let them play empirically with regimens because results would be the same. A more scientific and ethically sound application of the above results might be to establish a strategy of easily applicable regimens monitored in large scale trials whenever a new or tenable hypothesis is at hand. This could well be true for not only cancer of the ovaries but also similarly "resistant" situations. When no hard recommendations are at hand a positively sober, not just permissive, attitude should be enforced to minimise risks, false impressions, and waste of resources. Integrated periodical studies of quality of process and outcome seem to provide a promising tool for monitoring the real yield of delivered care specifically in cancer but also in all conditions where effective treatments are not the rule.

Supported by a grant from the Italian National Research Council, special project "Oncology," contract number 8400828.44 and a generous contribution from the Italian Association for Cancer Research, Milan, Italy.

We thank the following pathologists who made this study possible by providing access to pathological specimens: Professor Alessio,
Avellino; Professor Arrigoni, Treviso; Professors Bacci and Severi, Perugia; Professors Bancheri and Morino, Gorizia; Professor Barbieri Olivi, Foligno; Professor Bartolini, Pistoia; Professor Boccato, $S$ Donà di Piave; Professor Carloni, Conegliano Veneto; Professor Costa, Firenze; Professor Cristofori, Lecco; Professor Delendi, Pordenone; Professor Domenici, Carrara; Professor Linoli, Arezzo; Professors Lunetta and Nazari, Como; Professor Malfatti, Lucca; Professor Nigro, Sondrio; Professor Parini, Milan; Professor $\mathscr{\mathscr { A }}$ Rizzo, Padova; Professor Squartini, Pisa; Professor Tommasini, Magenta; Professor Tosi, Siena; Professor Turolla, Legnano; and $O$ Professor Zito, Rome; also $M$ D'Incalci for useful suggestions in drafting the text, Tiziana Castoldi for skilful help in preparing the manuscript, Anna Maria Chimienti for preparation of the bibliography, and Judy Baggott for revision of the English text.

\section{References}

1 Silverberg E. Cancer statistics, 1984. CA 1984;34:7-23.

2 Young RC. Chemotherapy of ovarian cancer: past and present. Semin Oncol $1975 ; 2: 267-76$

3 Fisher RI, Young RC. Chemotherapy of ovarian cancer. Surg Clin North Am 4 Anonymous. Management of advanced ovarian cancer [Editorial]. Lancet 1980

5 La Vecchia C, Franceschi S, Liberati A, Gallus G, Tognoni G. The clinical relevance of the epidemiology of ovarian cancer. Eur $\mathcal{f}$ Clin Cancer Oncol 1984;

6 Young RC, Decker DG, Wharton JT, et al. Staging laparotomy in early ovarian cancer. FAMA 1983;250:3072-6.

Liberati A, Andreani A, Colombo F, et al.
general hospitals. Lancet 1982 ;ii:258-60

iberati A, Confalonieri C, Andreani A, et al. Lung cancer care in general hospitals. Tumori $1983 ; 69: 567-73$.

9 Kottmeier HL. Annual report of the results of treatment in gynaecological cancers. Vol 18. Stockholm: International Federation of Gynecology and Obstetrics,

10 Liberati A, Masera G, Tognoni G, et al. Quality of cancer care evaluation in Italy. In: Mettlin C, Murphy GP, eds. Progress in cancer control IV. Research in the 1 McNeil BJ, Weichselbaum R, Pauker SG. Speech and survival. Tradeoffs between quality and quantity of life. $N$ Engl $f$ Med $1981 ; 305: 982-7$.

12 Tobias JS, Tattersall MHN. Doing the best for the cancer patient. Lancet 1985; i:35-8.

(Accepted 4 fune 1985)

\section{SHORT REPORTS}

\section{Role of fibreoptic bronchoscopy in management of pneumonia in acquired immune deficiency syndrome}

While Pneumocystis carinii pneumonia is the most common opportunist lung infection in patients with the acquired immune deficiency syndrome (AIDS), other viral, fungal, and bacterial infections occur frequently. ${ }^{1}$ The absence of clinical, radiological, or serological tests to differentiate these infections necessitates the use of fibreoptic bronchoscopy with transbronchial biopsy and bronchoalveolar lavage. This procedure appears to be safe for both patient and operator and results in diagnosis in over $85 \%$ of cases. ${ }^{2}{ }^{3}$ We report a study of 42 bronchoscopies in 30 patients at St Mary's Hospital showing the value of accurate diagnosis in patients with suspected AIDS complaining of pulmonary symptoms, who frequently have multiple, treatable opportunist infections.

\section{Patients, methods, and results}

Between June 1983 and July 1985,42 bronchoscopies were performed on 30 homosexual men with suspected AIDS. All the patients were positive for antibodies to human T cell lymphotropic virus type III (HTLV-III) by enzyme linked immunosorbent assay or membrane immunofluorescence. Patients presented with symptoms of persistent non-productive cough or dyspnoea on exertion, with or without abnormal chest $x$ ray appearances, hypoxia, or reduced carbon monoxide gas transfer. Thrombocytopenia or disordered coagulation was corrected and supplementary oxygen provided. Bronchoscopy was performed using a fully immersible Olympus BF 10 fibreoptic bronchoscope; the operator wore sterile gown, gloves, mask, and goggles. Bronchoalveolar lavage, using $100-180 \mathrm{ml} 0.9 \%$ saline in $20-50 \mathrm{ml}$ aliquots, was followed by transbronchial biopsy (without fluoroscopic control) in the area of lung with maximum radiological abnormality (if present).
The bronchoscope was disinfected with $2 \%$ glutaraldehyde for three hours after use.

Cytological, virological, and bacteriological examination of lavage fluid $\overline{\overline{0}}$ was performed using Gram, Ziehl-Neelsen, and Gomori's methenamine $\exists$ silver nitrate stain. Transbronchial biopsy tissue was pressed on to a slide to $\bar{T}$ make touch preparations for cytological studies; the remainder was placed in $\vec{F}$ formol saline for histological examination and in viral transport medium for culture.

Pn carinii was identified in 16 patients (table)-by transbronchial biopsy in 15 , by touch preparations in four, and by bronchoalveolar lavage in five. In four patients endobronchial Kaposi's sarcoma was seen; all four had cutaneous lesions. Infections with Mycobacterium tuberculosis, cytomegalovirus, Gram positive cocci (Streptococcus pneumoniae and Staphylococcus aureus), and 8 Candida albicans were identified in 11 patients; multiple infections were present in three. Negative findings with a strong clinical diagnosis of $P_{n}$ carinii pneumonia and prompt response to high dose co-trimoxazole were classified as false negative.

Early mortality-that is, within one month of bronchoscopy-occurred $\mathcal{N}$ in two patients with $P n$ carinii pneumonia, both of whom had concurrent cytomegalovirus infection; most patients (four out of five) with cytomegalovirus or candidal pneumonitis died within 28 days.

The procedure was well tolerated. Three patients developed pneumothoraces, one requiring drainage, and one patient bled $50 \mathrm{ml}$ after biopsy, $\omega$ requiring topical adrenaline.

Pathological findings in 42 bronchoscopies in patients suspected of having AIDS

\begin{tabular}{|c|c|c|c|c|c|}
\hline Diagnosis & $\begin{array}{l}\text { No of } \\
\text { cases }\end{array}$ & $\begin{array}{c}\text { Trans- } \\
\text { bronchial } \\
\text { biopsy }\end{array}$ & $\begin{array}{c}\text { Touch } \\
\text { preparations }\end{array}$ & $\begin{array}{l}\text { Broncho- } \\
\text { alveolar } \\
\text { lavage }\end{array}$ & $\begin{array}{c}\text { Mortality } \\
\text { (at 28 days) }\end{array}$ \\
\hline$P_{n}$ carinii pneumonia & 16 & 15 & $4 / 7$ & $5 / 12$ & 2 \\
\hline Kaposi's sarcoma & 4 & $2 / 2$ & - & - & 1 \\
\hline Gram positive cocci & 4 & $1 / 4$ & - & $3 / 4$ & 0 \\
\hline Myco tuberculosis & 2 & $1 / 2$ & $\overline{0 / 2}$ & $2 / 2$ & 0 \\
\hline $\begin{array}{l}C \text { albicans } \\
\text { Cytomegalovirus }\end{array}$ & $\begin{array}{l}2 \\
3\end{array}$ & $\begin{array}{l}2 / 2 \\
3 / 3\end{array}$ & $0 / 2$ & $\begin{array}{l}1 / 2 \\
1 / 2\end{array}$ & 2 \\
\hline False negative & 5 & - & - & - & 3 \\
\hline True negative & 9 & - & - & - & 0 \\
\hline
\end{tabular}

